\title{
BIPLANAR DOUBLE-SUPPORTED SCREW FIXATION METHOD IN OSTEOPOROTIC NECK OF FEMUR FRACTURES
}

\author{
Siddharth Gupta1, Vinit Yadav², Mohan Rao 3 \\ ${ }_{1}^{1}$ Senior Resident, Department of Orthopaedics, Rajawadi Hospital, Mumbai, Maharashtra, India. \\ ${ }^{2}$ Consultant, Department of Orthopaedics, Popular Hospital, Varanasi, Uttar Pradesh, India. \\ ${ }_{3}^{3}$ Medical Officer, Department of Orthopaedics, Rajawadi Hospital, Mumbai, India.
}

\begin{abstract}
BACKGROUND
Femoral neck fracture is one of the common injuries sustained by elderly population, who due to their age and comorbidities have an unsteady gait and lower bone mineral density, thus increasing the risk of fractures around the hip. The Biplanar DoubleSupported Screw Fixation technique used in neck-of-femur fractures, was developed by Dr. O. Filipov. This technique is a new method for fixing femoral neck fractures by means of screws placed in a particular fashion and in different planes. This technique is based on the concept of establishing two supporting points for the implants, and their biplanar special orientation in the femoral neck and head.
\end{abstract}

ABSTRACT

\section{METHODS}

This is a prospective case series study of 18 osteoporotic neck of femur fractures having average follow up of 14 months. It also took into account the complications. Outcomes were documented with conventional radiographs, modified Harris Hip Score (Harris HS) questionnaire, and two more indicators for independent living namely- relief of pain (good/poor), and wearing socks and shoes (easy/difficult), were taken into account.

\section{RESULTS}

Patients' demographic profile along with radiography, complications in terms of non-union/pseudoarthrosis, fixation failure, and avascular necrosis were very low. Majority of the patients had Harris hip score from good to excellent. Relief of pain and ability to wear socks and shoes were present in more than $80 \%$ of patients.

\section{CONCLUSIONS}

The technique-BDSF increases the fixation strength of fracture of neck of femur, has promising clinico-radiological results, and is a good method of treatment.

HOW TO CITE THIS ARTICLE: : Gupta S, Yadav V, Rao M. Biplanar double-supported screw fixation method in osteoporotic neck of femur fractures. J. Evolution Med. Dent. Sci. 2019;8(15):1251-1254, DOI: 10.14260/jemds/2019/278

\section{BACKGROUND}

Femoral neck fractures are common injuries sustained by elderly population who usually have unsteadiness of gait and reduced bone mineral density, thus predisposing to fracture. Elderly osteoporotic women are at greatest risk. It is anticipated that the total number of hip fractures will exceed 6 million people in 2014.[1] Under the conditions of severe osteoporosis, the femoral neck consists of cortical walls, enveloping soft cancellous bone, having unimportant mechanical significance, and the neck can often be looked at as a hollow cylinder.

The important drawbacks of osteosynthesis by internal fixation is the more number of patients requiring revision surgeries, and the greatest risk is for patients with displaced fracture.[2,3] The most important and common cause of revision surgeries is failure of fixation with secondary displacement of the fracture, leading to failure to unite (Nonunion) and femoral head avascular necrosis. ${ }^{[4]}$

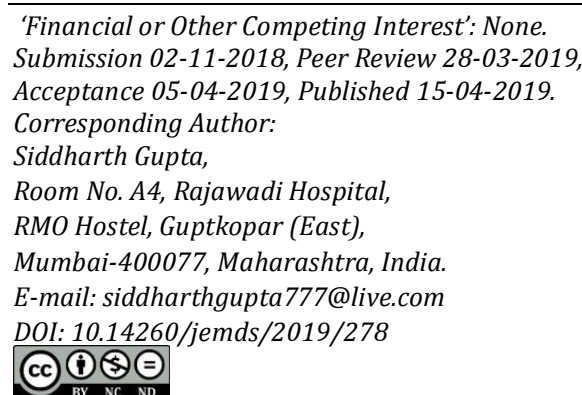

Neck of femur fractures osteosynthesis is associate with up to $46 \%$ rate of complications. [5,3] While the late avascular necrosis (AVN), ranging from 9 to $32 \%$, depends on various biological and surgical factors, the other common complication fixation failure, rating between 9 and 30\% is mainly due to insufficient fixation strength in osteoporotic bone.[6-9] The latter could be reduced by optimizing the primary stability of the internal fixation construct.

The Biplanar Double-supported Screw Fixation Technique used in fractures of femoral neck (BDSFTechnique), was developed by Dr. O. Filipov, is a newer technique of fixation by screws in fracture of femoral neck. It is pillared on a concept of the establishing of 2 different supporting position for the implants and their biplanar orientation in head and neck of femur. The femoral neck following fixation with screws requires support to the weight-bearing head portion, which would act like beam an overhanging edge, which must have 2 different supporting positions for the support of the head fragment. The technique of BDSF is based on this principle. This technique was original placement of 3 screws in 2 different planes, this technique caters the entry of 2 implants in the solid cortex of the proximal femoral diaphysis, which is more distally, and also relies on the strong neck of femur's calcar. They achieved 2 points of support by this technique. Thus, the position of distal screw and middle screw as well, in view of statics, turns them into a simple beam with an overhanging end, loaded by a vertical force. This beam with an overhanging end 
successfully supports the femoral head fragment, bearing the body weight and transferring it to the diaphysis.[10]

\section{Aim of The Study}

To evaluate the outcome of BDSF in case of osteoporotic femoral neck fractures.

\section{METHODS}

This is a case series type of prospective study of 18 osteoporotic neck of femur fractures with an average followup time of 14 months, taking into accounts also it's complications. The study was done in a tertiary care center. Informed consent was taken from all the patients. The patient aged from 50 years to 73 years. The subjects were divided according to garden classification. Frequency of distribution was Grade I - 2 patients (11\%), Grade II - 8 (44\%), Grade III - $5(28 \%)$ and Grade IV - 3(17\%). All the patients were offered BDSF. The study was started in august 2016 . We used three $6.5 \mathrm{~mm}$ self-tapping partially threaded steel cannulated screws. All patients received perioperative antibiotic prophylaxis. Every patient underwent spinal anaesthesia. Reduction technique was either closed (17 Patients) over fracture table or open technique through Watson jones approach (1 Patients). Surgical technique is that the first guide wire is inclined at an angle of $160^{\circ}-165^{\circ}$ from the shaft axis and directed from anterior to posterior and proximally, in a way it passes through the lower portion of femoral neck near the calcar closely on antero-posterior view, the guide wire goes to the posterior 3rd of head of femur and comes close to the posterior part of neck (On lateral view). The central guide wire is placed after the first. The central guide wire entry, according to on the caput-collum-diaphyseal angle, is about $2.0-4.0 \mathrm{~cm}$ above from the first guide wire. This second guide wire is angled at $130^{\circ}-135^{\circ}$ from the shaft axis and is directed anteriorly and proximally, in a way that it passes close to the calcar, the second guide wire is directed to the anterior 3rd of the head of femur on lateral view and into the lower 3rd of the head of femur on anteroposterior view. Thereafter, put the third and the proximal guide wire, with its entry starting at $1.5-2.0 \mathrm{~cm}$ above the second wire. This wire should be parallel to the second wire. The third wire is placed in the anterior 3rd of head of femur on a lateral view and in the superior 3rd portion of head of femur on Anteroposterior view. Every case was started with early mobilization after surgery and allowed to touch toes for initial 4 weeks, next 4 weeks with partial weight bearing and then full weight bearing, without limitations in the range of motion. All patients were encouraged for physiotherapy for early mobilization.

Regular follow-ups were taken in form of clinical examination, x-rays for healing process and using the modified Harris hip score (Harris HS) questionnaire for documenting the results. On follow-up, x-rays were looked for signs of bony callus, malunion, non-union and avascular necrosis. Further clinical examination was done by Harris HS, 2 other indicators were also evaluated in terms of relief of pain which could be good or poor and putting on socks and shoes skills which could be easy or difficult.

\section{RESULTS}

The patients subjected in the study, there sex distribution were 5 males (31\%) and 13 females (69\%), averaged aged $62.2 \pm 3$ years (range 50-73). The follow-up period was 16 months on an average (Range 12-18), taking into account all its complications. Out of 18 patients who were operated two of them developed post-operative serous discharge which was managed by regular dressing and upgrading antibiotics. In follow-up 1 patients (5.6\%) patients developed pseudoarthrosis/non-union, 1 patient (5.6\%) developed fixation failure probably due to early weight bearing in an osteoporotic bone and psychological aspect of old age in their follow-up.

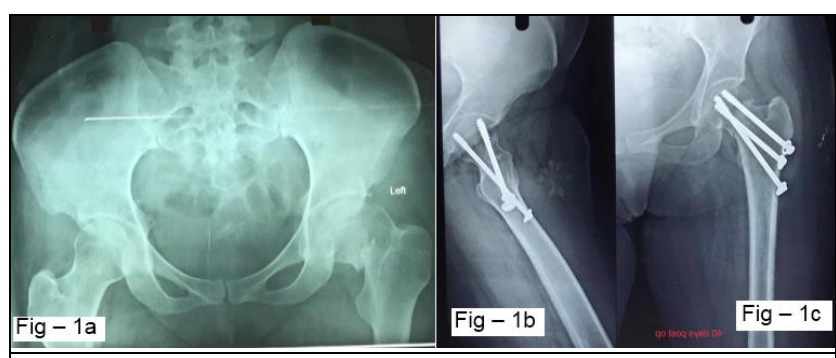

Figure 1a. Pre-Operative 62 Years Female with One Day Old History of Fall with Fracture Neck of Femur.

Fig 1 b \& 1c. Post-Operative- Fixation Done with BDSF Technique

On evaluation the complications of Avascular Necrosis, if found in an average of 12 months 2 patients (11.1\%) developed. This could be explained as the patients of this complication were Garden Classification type III/IV fracture making them more prone to vascular injury, also it was more common in patients undergoing open surgery as compared to closed.

On evaluating Harris HS majority of patients about $80 \%$ patients had excellent to good score.

\begin{tabular}{|c|c|c|}
\hline Harris HS & Frequency & Percentage \\
\hline Excellent & 6 & $33.3 \%$ \\
\hline Good & 9 & $50.0 \%$ \\
\hline Fair & 2 & $11.1 \%$ \\
\hline Poor & 1 & $5.6 \%$ \\
\hline
\end{tabular}

Pain relief was reported good among 16 patients (88.9\%) and poor in 2 patients (11.1\%). On evaluating putting on shoes and socks in these patients - 15 patients (83.3\%) found it easy and 3 patients (16.7\%) found it difficult.

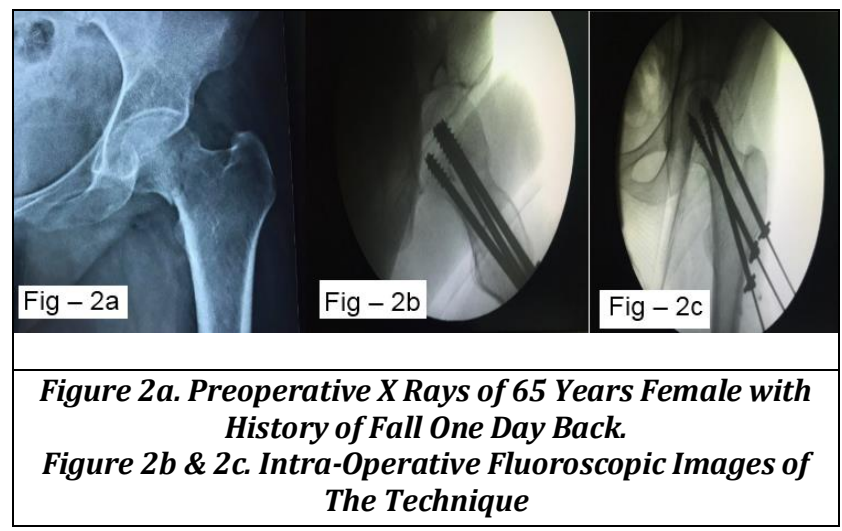



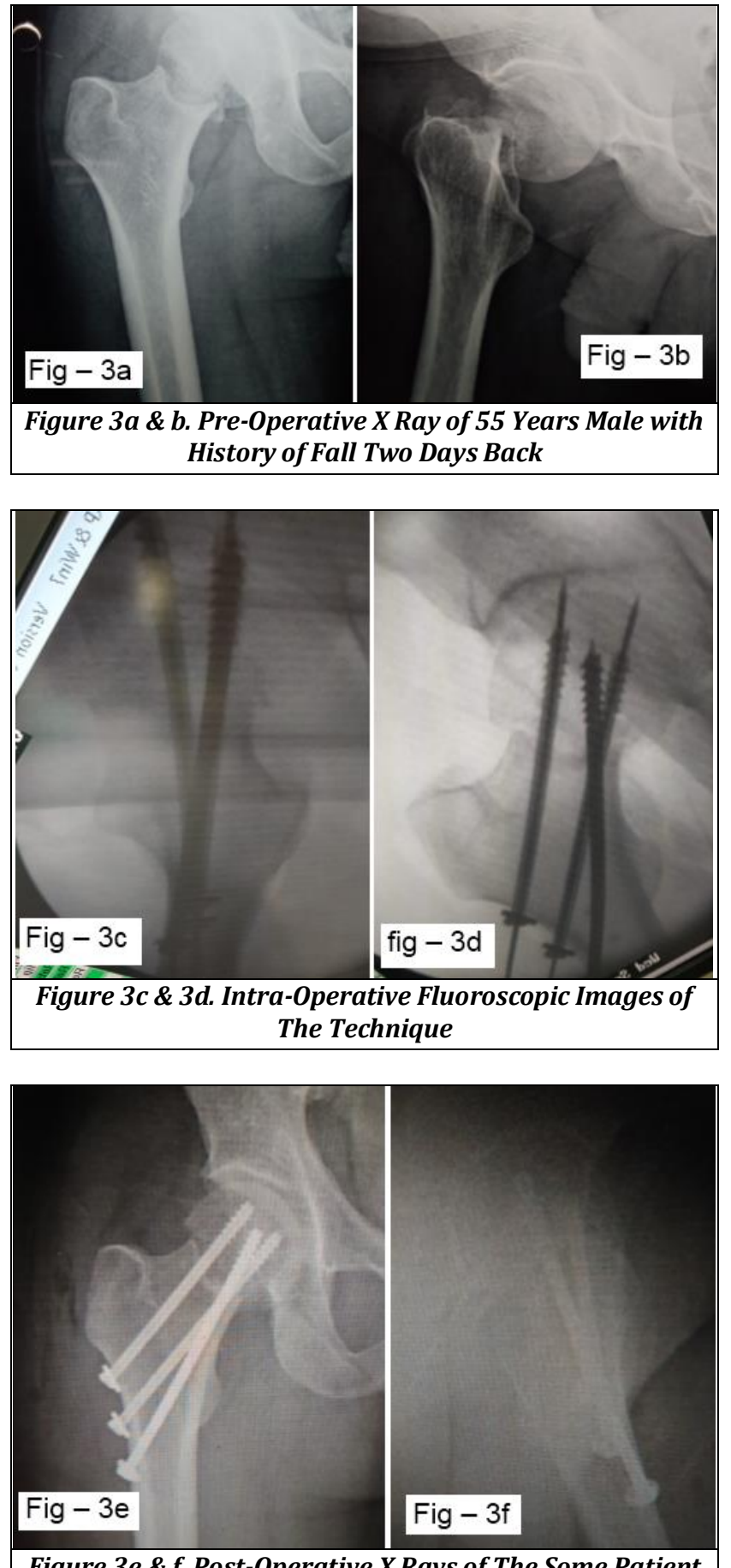

Figure $3 e$ \& f. Post-Operative X Rays of The Some Patient

\section{DISCUSSION}

The results in femur neck fracture treated with the BDSF method described by Dr. Filipov is more gratifying as compared to conventional screw fixation mentioned in literature.

The proximal femur anatomy usually does not allow more than three screws to be placed simultaneously, being parallel to each other; placing towards the cortical part around neck of femur and on the same instance having the screw entry distally position, in the hard diaphyseal cortex of the proximal femur, so that it avoids the entry from relatively weaker lateral metaphyseal cortex. The conventionally used technique of placing of three parallel screws in position, the entry point of the screw if placed distally, it will make an angle which is more obtuse with the shaft and places in an oblique manner in relation to the neck of femur. If the angle is made more obtuse by placing the screw in diaphysis, the neck of femur surface neck cross section is decreased in a geometrical way, and on practical purpose, placing more than one screw becomes difficult. Moreover, reliable stability is not achieved in all the planes on placement of only 2 screws.[11]

Such issues can be tackled by biplanar technique of screw placement with the concept of placing the 3 screws in 2 planes and in an obtuse angle. This technique allows the efficient weight bearing by successfully transferring weight from the head of femur onto the diaphyseal shaft by providing two steady supporting points and the obtuse angle of placement of the screws, this takes into account the strength of screws, even in a osteoporotic patient's bone. The technique of the implant placement helps in minimal risk of displacement and helps them to slide under stress. The results which was obtained with this technique-BDSF in view of fracture union are much better than the results with conventional methods of fixation. Garden, [12] like others before, further developed the concept that the implants must be placed more vertically, similar to the direction of the medial compression lamellae of the internal trabecular. The technique-BDSF ensures steady fixation, early mobilization and good future outcomes.

On reviewing the literature for traditionally used technique of fracture fixation, the reported bony union rate is around $84 \%$ (ranging from $54 \%-82 \%$ ), pseudoarthrosis or a nonunion rate of about $18 \%-46 \%$, and most importantly the failure of fixation rates ranging from $9 \%-30 \% \cdot[4,5,3,9,13,14,15]$

The avascular necrosis rates appears to be almost equal all over the world and is not much affected by the fracture fixation technique, which rates to about 9\%(ranging from $6 \%-19 \%$ ) for undisplaced and about $16 \%$ ( ranging from $9 \%-$ $32 \%$ ) for displaced fractures. $[4,6,8]$ The conventional technique of fracture fixation have moderate or severe pain in $30 \%-43 \%$ of the subjects, relief of pain in about $70 \%$ is good, good mobility in $63 \%$ and poor mobility rate in $37 \% .[4,3]$

This study had higher rate of bone union of about $90 \%$, lower incidence of nonunion of about $7 \%$ and mainly failure of fixation in only $2.6 \%$, this study shows that the techniqueBDSF has significantly better results compared to the data obtained from literature using conventional technique. As it is evident in our study, in terms of rates of AVN and pain as compared to literature.

Limitations of this study are for diagnosis of AVN no imagining modalities like CT or MRI scans were done, it was only assessed on x- ray films. There no control group with application of conventional technique of cannulated screws fixation with our study. Moreover, to the results published recently on biomechanical comparative study, our clinical study reconfirms that there is better outcomes following technique-BDSF treatment which is due to superior fixation strength.[5]

Technique-BDSF allows for early weight-bearing due to its diaphyseal cortical support, which is stronger and increased angle of screw placement, which is shown in the better Harris HS functional results and better daily living abilities of the subjects. 


\section{CONCLUSIONS}

The technique-BDSF increases the fixation strength of fracture of neck of femur. It has promising clinico-radiological results and is a good method of treatment.

\section{REFERENCES}

[1] Kannus P, Parkkari J, Sievänen H, et-al. Epidemiology of hip fractures. Bone 1996;18(Suppl 1):57S-63S.

[2] Frihagen F, Nordsletten L, Madsen JE. Hemiarthroplasty or internal fixation for intracapsular displaced femoral neck fractures: randomized controlled trial. BMJ 2007;335(7632):1251-4.

[3] Rogmark C, Johnell O. Primary arthroplasty is better than internal fixation of displaced femoral neck fractures: a meta-analysis of 14 randomized studies with 2,289 patients. Acta Orthop 2006;77(3):359-67.

[4] Lu-Yao GL, Keller RB, Littenberg B, et al. Outcomes after displaced fractures of the femoral neck. A metaanalysis of one hundred and six published reports. J Bone Joint Surg Am 1994;76(1):15-25.

[5] Gjertsen JE, Vinje T, Engesaeter LB, et al. Internal screw fixation compared with bipolar hemiarthroplasty for treatment of displaced femoral neck fractures in elderly patients. J Bone Joint Surg Am 2010;92(3):619-28.

[6] Damany DS, Parker MJ, Chojnowski A. Complications after intracapsular hip fractures in young adults. A meta-analysis of 18 published studies involving 564 fractures. Injury 2005;36(1):131-41.

[7] Loizou CL, Parker MJ. Avascular necrosis after internal fixation of intracapsular hip fractures: a study of the outcome for 1,023 patients. Injury 2009;40(11):11436.
[8] Nikolopoulos KE, Papadakis SA, Kateros KT, et al. Long-term outcome of patients with avascular necrosis, after internal fixation of femoral neck fractures. Injury 2003;34(7):525-8.

[9] Parker MJ, Raghavan R, Gurusamy K. Incidence of fracture-healing complications after femoral neck fractures. Clin Orthop Relat Res 2007;458:175-9.

[10] Filipov 0. Biomechanics of the fractured femoral neck - the new bdsf - method of positioning the implant as a simple beam with an overhanging end. August 1st, 2012. http://dx.doi.org/10.5772/47839.

[11] Walker E, Mukherjee D, Ogden AL, et al. A biomechanical study of simulated femoral neck fracture fixation by cannulated screws: effects of placement angle and number of screws. Am J Orthop (Belle Mead NJ) 2007;36(12):680-4.

[12] Garden RS. Low-angle fixation in fractures of the femoral neck. J Bone Joint Surg Br 1961;43-B(4):64763.

[13] Asnis SE, Wanek-Sgaglione L. Intracapsular fractures of the femoral neck. Results of cannulated screw fixation. J Bone Joint Surg Am 1994;76(12):1793-803.

[14] Leonardsson O, Sernbo I, Carlsson A, et al. Long-term follow-up of replacement compared with internal fixation for displaced femoral neck fractures: results at ten years in a randomised study of 450 patients. J Bone Joint Surg Br 2010;92(3):406-12.

[15] Skinner PW, Powles D. Compression screw fixation for displaced subcapital fracture of the femur. Success or failure? J Bone Joint Surg Br 1986;68(1):78-82. 